\title{
Study on the Environmental Psychology and Modern Interior Design
}

\author{
Min Wang \\ Nanyang Institute of Technology, Nanyang, Henan, 473000
}

Keywords: Modern Interior Design, Environmental Psychology, Fashion Show

\begin{abstract}
As a comprehensive subject, modern interior design involves many aspects such as engineering, ecology and environmental psychology. Its design essence is to realize the comfort of people's living environment. Environmental psychology is an indispensable component of modern interior design work. The reason is that the starting point of interior design is the living environment of people. It is necessary to consider the comfort of people and design from the actual situation of individuals. Being able to master the relevant environmental psychology knowledge is difficult to have a relatively clear understanding of the person's psychological state, then the interior design will lose its practical significance.
\end{abstract}

\section{Introduction}

With the development of society and the improvement of people's living standards, people have put forward higher requirements in interior design. Modern interior design covers a wide range of disciplines, such as art, engineering, and environmental psychology. Therefore, modern interior design is a discipline formed by a combination of various disciplines. When conducting education and teaching activities in such subjects, the main purpose is usually to create a comfortable and harmonious living environment for users. At this time, it is necessary to play the role of environmental psychology to analyze and explore the changes in people's minds in different environments. Combine the scientific and artistic elements of environmental elements, and scientifically and rationally design the indoor environment to create a more satisfactory indoor environment for people. So how do you play the role of environmental psychology in modern interior design to ensure the safety and comfort of people's indoor environment? Therefore, the modern interior design and environmental psychology were studied, and the influence of environmental psychology on modern interior design was analyzed, and people's requirements for interior design were met as much as possible to improve people's quality of life and environment.

\section{Environmental Psychology and Modern Interior Design Connotation}

Environmental psychology refers to the use of people's psychological changes and other characteristics to improve their living environment, and strive to create an environment suitable for people's lives. When studying environmental psychology, it usually comes from two perspectives, namely environmental science and psychology. From a psychological point of view, its main role is to study people's cognitive ability to things, as well as psychological changes, personality characteristics, emotional attitudes, etc. After research, analysis and summary of people's inner needs, and then in the interior design In the process, we can create an indoor environment that meets people's requirements based on people's psychological characteristics. From the perspective of environmental science, people can make various changes in the surrounding environment. At the same time, the changed environment will also have a certain impact on people's emotional attitudes. The elements in the indoor environment are relatively standardized and have certain patterns. Different indoor environments will have different influences on people's emotions and other manufacturers. Therefore, when designing the indoor environment, it is necessary to consider the environment and the changes in people's minds. The relationship between interactions.

Modern interior design means that the indoor elements can be reasonably matched and transformed without affecting the safety performance of the house and other related requirements, 
and the artistic atmosphere of the interior can be reflected by other means to create a science for people. The practical, safe and beautiful indoor environment meets people's requirements for high quality of life. The modern interior design is mainly considered from the following aspects to ensure that the scientific and artistic aspects of these aspects can create an environment more suitable for people's lives and work. First of all, we must take into account the use of indoor space, make rational use of space, give full play to the spatial imagination, and provide more space for the design of indoor environment to create better visual effects. Next, we must design the interior decoration and use the appropriate decoration materials to fully reflect the superiority of the environment. For example, various colors of paint will make the interior design have different effects. Therefore, it should be based on people's pursuit of the indoor environment. More in line with the requirements of the house environment. Finally, it is necessary to take into account the placement of various objects in the house, which need to be reasonably designed to make full use of the space without making the interior look crowded. Learn more about the size and function of each object, and how much people need it. After analysis, arrange the position of each object to achieve the practicality and artistry of each object, and add more beautiful elements to the indoor environment. .

\section{The problem of environmental psychology in modern interior design}

Today, with the gradual development of society, China has paid more attention to the study of environmental psychology. However, because China's research on environmental psychology is still in an insufficient stage, its influence in modern interior design is small and cannot be fully exerted. Out of its essential function. In addition, with the gradual improvement of people's indoor environment requirements, modern interior design has also begun to turn to the development direction based on environmental psychology. However, under such conditions, people's requirements for living and working environment are not fully met. The reasons for this situation are mainly as follows: First, economic conditions are not allowed. People often want to make their indoor environment more suitable for their own needs, but the realization of this demand requires too much material conditions, so people can not pursue their own high quality indoor environment. Second, people's high demands on the indoor environment are often difficult to express in words, and it is impossible for interior designers to understand their needs for the indoor environment. This may result in the interior design effect being completely inconsistent with the user's requirements, resulting in unnecessary Loss. Third, due to the limitations of the interior design scheme, people are unable to exert a richer imagination, and the demand for a good indoor environment will be limited, resulting in a reduction in the effect on interior design and the inability to achieve internal recognition of the indoor environment. . From this point of view, in the process of interior design, various constraints make environmental psychology difficult to play a greater role, leading to modern interior design can not provide people with a more qualified living environment, seriously affecting people at work The emotional attitudes in life affect people's living standards.

\section{People's psychological behavior in the environment}

People have certain differences in language expression and rational thinking, which leads people not to be disturbed in activities. In different activities, people need different places. In the design of indoor environment, people must keep certain The space, but also according to different contact objects, in different occasions, the difference in distance. People in different environments, the psychological state will also change, people's psychology and the environment are still closely related, people hope that what they want not to be influenced by the environment, not to be disturbed by outside things, just The indoor environment is a relatively closed space, and people can create a distance between the indoor and the outside space so as not to be disturbed. Interior designers should fully consider this when designing, so that people and the environment must have a certain degree of intimacy, but also to maintain distance, so that people can feel the beauty of the space. For example, when students choose a dorm bed, they usually choose the location of the 
corner instead of the location close to the door. It is because people's psychological factors determine that people do not want to be disturbed by the outside environment. In the process of rest, people are indoors. Therefore, from the perspective of environmental psychology, people are more likely to get a good rest indoors.

When designing interiors, it is not as broad as possible. People need a kind of support in the interior space to get a sense of security. For example, in the train station, people do not like to stay in the waiting room for a long time, but prefer to stay in the place where the crowd is scattered, and properly keep a distance from a large number of people.

When people are active in indoor space, they generally prefer to be in a bright place. People will drive from the dark to the bright place. Therefore, when designing the public environment, make sure that the light is bright and can be marked. illumination.

The design of the indoor environment is in line with people's psychological characteristics and behavior patterns. For example, for some modern large-scale shopping malls, the interior design must take into account customers. The customer's shopping has evolved from a single shopping to a shopping, leisure, excursion, service, and information. Therefore, this kind of change requires that customers should be as close as possible to the goods, so that they can choose and compare them. Therefore, the modern shopping mall interior design is arranged around the choice and the open frame, combined with amusement, teahouse, Child care and other facilities.

Psychological behavior patterns and cognitive environments provide some hints for interior space design. The sensory organ receives initial stimulation in the environment and the brain responds in the environment. Therefore, the perception of the environment is that the brain works with the sensory organs. After the combination of cognitive environment and psychological behavior, the designer does not simply design the basis from the human scale, use function, etc., has space, determines its shape and scale range, and then chooses the color tone and illumination.

In the interior design, the user's personality and the relationship with the environment should be fully considered. In general, environmental psychology can affirm that people have similar or even the same response to the relevant perceptions of the outside world, but should also fully consider the user's personality, behavior, and relationship with the environment. When shaping the environment, we must fully respect it. In addition, we can use the environment to "guide" some behaviors of people, and guide the impact on individuality, even to a certain extent. Designers must grasp reasonable scales when designing interiors.

Human psychology plays an important role in interior design. Moreover, interior design must be practical, have a certain use function, and must have perfect use functions while satisfying people's aesthetics, so that people can live comfortably indoors. In the process of interior design, not only must meet the material function of the design, but also meet the spiritual function of the design, to satisfy people's spiritual enjoyment, and use reasonable design to mobilize people's senses, so that people can feel at home indoors. work and life. When designing interiors, it must be in accordance with objective laws, not excessive exaggeration. In design, it should be within the acceptable range of people, and also according to the crowd to carry out interior design. For example, young people may prefer personalization. The design, however, the elderly prefer a comfortable life, try to design some traditional elements in the design process.

\section{Conclusion}

When designing interiors, we must take into account people's subjective feelings. Nowadays, people's living standards are getting higher and higher, people are pursuing spiritual enjoyment more and more, and their living comfort requirements are getting higher and higher. Indoor environment It is the focus of people's attention. Therefore, in interior design, environmental psychology should be fully utilized to analyze from the perspective of environment and human psychology, so that people can design styles that people can enjoy in a more comfortable environment. Life, and, when the room is relatively empty, you can put some furniture to make the room feel better, so that people can feel the warmth of home. Moreover, in the interior design, we must fully consider the aesthetic requirements of people of different ages, young people are more 
individualistic, while the elderly pursue traditional design.

\section{References}

[1] Wang Zhiyong. Analysis of Environmental Psychology and Modern Interior Design [J]. Popular Literature, 2014, 12: 122.

[2] Wang Guangli. Analysis of environmental psychology and modern indoor design [J]. Industrial Construction, 2013, 16:279.

[3] Guan Huiming. On Environmental Psychology and Modern Interior Design-Residential Interiors [J]. Architectural Knowledge, 2012, 31:183.

[4] Wang Yi. Environmental Psychology and Modern Interior Design [J]. Architectural Knowledge, 2011, 11: 183.

[5] Deng Guohuang, Mu Yaping, Wang Hongbin, Han Weisheng. Discussion on the design of modern kitchen [J]. Journal of Northwest Forestry University, 2008 (02). 